Mikalef, P., Pateli, A., Batenburg, R.S., Wetering, R. van de. Purchasing alignment under multiple contingencies: a configuration theory approach. Industrial Management and Data Systems: 2015, 115(4), 625-645

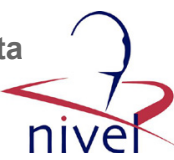

\begin{tabular}{|l|l|}
\hline $\begin{array}{l}\text { Postprint } \\
\text { Version }\end{array}$ & 1.0 \\
\hline Journal website & http://www.emeraldinsight.com/doi/abs/10.1108/IMDS-10-2014-0298 \\
\hline Pubmed link & $10.1108 /$ IMDS-10-2014-0298 \\
\hline DOI & .
\end{tabular}

This is a NIVEL certified Post Print, more info at http://www.nivel.eu

\title{
Purchasing alignment under multiple contingencies: a configuration theory approach
}

\author{
PATRICK Mikalef AND AdAMANTIA PATEli DePARTMENT Of INFORMatics, IONIAN \\ UNIVERSITY, CORFU, GREECE, AND RONALD S. BATENBURG AND ROGIER VAN DE \\ WETERING INSTITUTE OF INFORMATION AND COMPUTING SCIENCES, UTRECHT UNIVERSITY, \\ UTRECHT, THE NETHERLANDS
}

\begin{abstract}
Purpose - Strategic alignment is a theory-based state that is considered as crucial for organizations in order to realize performance gains from information technology (IT) investments and deployments. Within the domain of purchasing and supply chain management there has been a growing interest on how purchasing strategy can be effectively aligned with IT and what conditions facilitate this state. The purpose of this paper is to investigate complex causal relationships of contingency elements that are key in enabling the "fit" between purchasing strategy and IT.

Design/methodology/approach - The paper employs a configuration theory approach and propose that purchasing alignment is dependent upon patterns of multiple contingencies. In adherence with contingency theory, the authors group these elements as relating to strategic orientation, organizational factors, and purchasing decisions. On a sample of 172 international companies the authors then apply the novel methodology of fuzzy set qualitative comparative analysis (fsQCA).

Findings - The paper empirically demonstrates that depending on the strategic orientation that a company follows, there are alternative combinations of elements that lead to high purchasing alignment. For companies following an operational excellence strategic orientation, a high contract binding scheme, or a small firm size facilitates purchasing alignment. Enabling elements for product leadership companies include a decentralized purchasing structure, a broad supplier base, and a large firm size. Purchasing alignment for customer intimacy companies is supported by a centralized purchasing structure, loose contract binding, and a large supplier base.

Practical implications - The findings of this study suggest that practitioners aiming to attain a state of purchasing alignment should consider a number of contingency elements in the process. The paper shows that there is equifinality
\end{abstract}


Mikalef, P., Pateli, A., Batenburg, R.S., Wetering, R. van de. Purchasing alignment under multiple contingencies: a configuration theory approach. Industrial Management and Data Systems: 2015, 115(4), 625-645

in the configurations that lead to purchasing alignment. This means that attaining purchasing alignment is dependent upon various clusters of contingency elements which must be taken into account when formulating a purchasing strategy.

Originality/value - In contrast with past studies examining purchasing alignment as a result of the isolated impact of several antecedents, we applied a configuration theory approach to demonstrate that it is facilitated by the combined impact of a set of cause-effect relationships. In cases were non-linear and synergistic relationships exist between independent variables, this type of research may be a viable alternative.

\section{INTRODUCTION}

Over the past years, an increasing amount of organizations invested large proportions of their revenues on information technology (IT) with the aim of outperforming their competitors. Many scholars argue that investments in IT along with structured adoption and use can potentially generate many advantages for organizations (Devaraj and Kohli, 2003). However, despite heavy investments in IT, organizations quite often fail to achieve improvements in their organizational performance due to their inability to align IT with organizational needs. In general, this so called productivity paradox (Solow, 1987), has been mostly attributed to the lack of fit, or else alignment, between business strategy and internal resources including IT (Chan et al., 2006). Both in scientific literature and in practice, it is a well-known fact that achieving a state of business-IT alignment is a crucial step in order to leverage the maximum potential benefits of IT (Henderson and Venkatraman, 1993; Papp, 1999). With companies spending a large part of their revenues on supply chain related activities, there is a growing interest in the potential value of supply chain management (SCM) systems (Presutti, 2003; Batenburg and Versendaal, 2008). The problem of misaligned IT, however, also occurs in the area of purchasing and SCM, with practitioners striving to increase the associated value of their investments (Heckman, 1999). Efforts by IT executives are hindered due to the lack of domainspecific quantitative research, leaving them with scarce guidance on how to align IT with purchase requirements (Batenburg, 2007). Literature notes that purchasing alignment positively impacts performance, however, the facilitating conditions that enable this fit are not described (Mikalef et al., 2014). It is recognized that the full value of purchasing systems can only be realized if activities and decisions are aligned with a firm' s strategic orientation and capabilities (Baier et al., 2008). Hence, there is a need to examine the synergies that exist between elements of the internal and external environment and how their overall effect shapes purchasing alignment.

We posit that contingency factors should be considered in a holistic manner when assimilating any IT system. Therefore, we examine alignment under the contingency lens of: strategic orientation, organizational factors, and purchasing decisions (Milgrom and Roberts, 1995). Hence, this study explores the three-way dynamics that influence alignment in the purchasing and SCMdomain (purchasing alignment). 
Mikalef, P., Pateli, A., Batenburg, R.S., Wetering, R. van de. Purchasing alignment under multiple contingencies: a configuration theory approach. Industrial Management and Data Systems: 2015, 115(4), 625-645

To do so, we apply a configuration theory approach which is aimed at discovering complementarities between elements, and how they, as patterns, lead to specific outcomes (El Sawy et al., 2010). Therefore, we base our research on the Gestalt perspective which seeks to discover clusters of attributes that facilitate fit (Venkatraman, 1989). Consequently, our research question can be formulated as follows:

RQ1. What configurations of strategic orientation, structure and purchase decisions lead to enhanced purchasing alignment?

Rather than implying that alignment is an outcome of singular causation and linear associations, this study seeks the different configurations of elements that enable business and IT "fit". Therefore, the main differentiation is that we perceive purchasing alignment as resulting from more than one possible paths.

The rest of the paper is structured as follows. Section 2 presents the theoretical background of our research and discusses past findings relating to contingency elements.

Section 3 introduces the methodology applied to test the research propositions, while in Section 4 the results of the statistical analyses are put forth. The paper concludes with discussion of results and proposals for future research.

\section{THEORETICAL BACKGROUND}

\subsection{Configuration theory in information systems (ISs) research}

The dominant research paradigm within the IS domain has been divided into variance theories and process theories (Gregor, 2006). Variance theories' practical use lies on their ability to predict relationships between outcomes and predictor variables.

The main proposition is that each single cause has its own independent effect, which may comprise of one or more predictors. Despite their contribution to the IS field, variance theories have limited value when applied to cases of mutual causality and fuzzy boundaries (El Sawy et al., 2010). The main limitation of variance theories is that they only allow for unifinality, i.e. situations where an outcome is determined by a specific value of its predictors. This implies that a given outcome cannot be a result of more than one combination of causal effects (Fiss, 2007). The second class of theories, i.e. process theories, are particularly helpful in examining how outcomes change over time. Their significance lies in that they are able to explain how an outcome variable changes through a predefined period and what aspects triggered that change. However, the pitfall of process theories is that they are unable to capture a holistic systemic effect, where the outcome of the predictor variable requires the examination of the properties of numerous interdependent predictors. Configuration theory is a newly applied approach in the field of IS which is best suited for studying holistic interplays between elements of a messy nature (Fiss, 2007).

Such approaches were until recently applied primarily in organizational research studies. The aim of configuration theory is to identify patterns and combinations of variables and reveal how their synergistic effects lead to specific outcomes. Configurations occur by different combinations of causal variables that affect an 
Mikalef, P., Pateli, A., Batenburg, R.S., Wetering, R. van de. Purchasing alignment under multiple contingencies: a configuration theory approach. Industrial Management and Data Systems: 2015, 115(4), 625-645

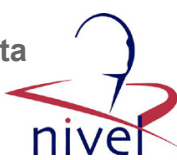

outcome of interest (Rihoux and Ragin, 2009). The main difference of configuration theory is that it views elements through a holistic lens that must be examined simultaneously, and is therefore particularly attractive for context-related studies of the IS strategy field examining complex causality. In contrast with variance and process theories applied in IS research, configuration theory supports the concept of equifinality, meaning that the same outcome can be a result of one or more sets of configuration patterns (Fiss, 2007). Additionally, configuration theory includes the notion of causal asymmetry, meaning that the combination of elements leading to the presence of an outcome may be quite different than those leading to an absence of the outcome (Fiss, 2007).

The limited application of configuration theory in academic literature to date can be credited to the lack of appropriate methodologies for rigorous and meaningful data analysis. Despite these shortcomings, recent advances in methodologies and statistical tools go beyond identifying effective configurations, and enable researchers to extract core elements of configurations along with their interdependencies. Thus, it is feasible to analyze data that correspond to a greater degree to reality. These improvements allow for a more detailed understanding through fine-grained results that are applicable in practice. Research applying fuzzy set qualitative comparative analysis (fsQCA) is still in its infancy, mainly due to the relatively recent introduction of the methodology. However, lately there has been a stream of research in this direction, with a small number of papers focused on the IS management discipline (El Sawy et al., 2010; Park and El Sawy, 2012).

\subsection{Purchasing alignment}

Within the SCM field, purchasing alignment is considered as a desired state which business executives should strive to achieve (Wong et al., 2012). Literature recognizes that the full value-creation potential of the purchasing function can only be attained if decisions, activities, investments, and strategy are aligned (Baier et al., 2008).

The importance of purchasing alignment is confirmed by empirical studies which demonstrate that firms that manage to align their purchase function perceive increased financial and operational performance (Cousins, 2005; Mikalef et al., 2014). With the emergence of IT systems that support the purchasing function, the challenge of aligning them with strategy and activities of the supply chain has occupied researchers (Thun, 2010). This need is reinforced by studies which indicate that simply investing in IT does not result in any performance gains (Chae et al., 2014). Building on the strategic alignment and business-IT alignment literature, Beukers et al. (2006) propose a framework of purchasing alignment based on the balance between five functional domains of the procurement process; strategy and policy, organization and processes, monitoring and control, people and culture, and IT. The main idea is that management should aim for coherency of the level of maturity for each of these areas. Recognizing the importance of attaining a state of alignment between functional domains and IT, researchers have been motivated to study the conditions under which this state can be realized and sustained (Peak et al., 2005).

Numerous studies have pinpointed that the degree of alignment which companies achieve is dependent upon a number of organizational and contextual elements (Cragg et al., 2002; Batenburg and Versendaal, 2008). These types of studies fall 
Mikalef, P., Pateli, A., Batenburg, R.S., Wetering, R. van de. Purchasing alignment under multiple contingencies: a configuration theory approach. Industrial Management and Data Systems: 2015, 115(4), 625-645

under the contingency view, a broad class of theories that have primarily been applied in the strategic management literature. According to contingency theory there is no optimal way to manage, but rather, each situation is dependent upon numerous internal and external elements (Donaldson, 2001). Under the contingency lens, alignment has been found to be affected by a number of elements, including strategic orientation, organizational factors, as well as other contextual or situational elements (Chan and Reich, 2007). Despite the significance of findings at a generic firm level, recent publications have recognized the importance of more fine-grained approaches, focusing on specific domains (Cragg et al., 2002), IT systems (Ho et al., 2004), IT architectures (Mikalef and Pateli, 2011), and even economic regions (Chen, 2010). The rationale for opting for such approaches is that alignment may have antecedents and outcomes that are contingent upon certain contextual and organizational elements. Concerning the domain of SCM, studies have shown that several contingency elements contribute in shaping purchasing alignment, which among others include organizational structure, business strategy, and purchasing decisions (Baier et al., 2008; Sousa and Voss 2008; Wong et al., 2012). Building on these findings, we apply the principles of configuration theory in order to determine under what combinations of these elements high levels of purchasing alignment are attained.

\subsubsection{Strategic orientation.}

Strategic orientation can be categorized in many ways based on the level of aggressiveness (Miles and Snow, 1978), the different value propositions they offer (Treacy and Wiersema, 1993), or the competitive advantage scheme (Porter, 1980) which a company follows. Much has been written over the years on the topic of situational factors that companies must pay attention to in order to gain a competitive edge when following their respective strategic orientation (Thompson et al., 2008). Tan (1995) empirically demonstrated that depending on the strategic orientation a company followed, different uses of IT emerged. In order to capture the different types of strategic orientations, we apply the widely used classification of value disciplines (Treacy and Wiersema, 1993). According to this perspective, there are three main strategic orientations which each exhibiting different clusters of elements that enable fit (Tallon, 2007). Operational excellence companies focus on delivering products/services to companies at competitive prices and with minimal inconvenience.

Hence, the focus is on reducing overhead costs, reduce transaction and other friction costs" , and optimize business processes across functional, and organizational boundaries.

Product leadership companies strive for state-of-the-art products and services. For such companies the focus is on continuously pursuing new solutions to new problems, making agile collaboration, and supply a cornerstone issue. Finally, customer intimacy companies continually tailor and shape their products and services according to customer requirements. Companies adhering to the customer intimacy strategic orientation, disregard cost in order to fulfil customer demands, and therefore forge ad-hoc relationships with suppliers. The importance of strategic orientation on purchasing alignment is noted in numerous studies, according to which, different profiles of elements support different business strategies. Based on the above, we 
Mikalef, P., Pateli, A., Batenburg, R.S., Wetering, R. van de. Purchasing alignment under multiple contingencies: a configuration theory approach. Industrial Management and Data Systems: 2015, 115(4), 625-645

consider that there is a specific profile of choices for each type of strategic orientation which is coherently supported by IT within the SCM domain.

\subsubsection{Organizational structure and size.}

Organizational structure has been conceptualized in literature in various ways and includes activities of task allocation, coordination, and supervision, which are directed towards the achievement of organizational gains (Zheng et al., 2010). Most studies examine structure in terms of distribution of authoritative power and measure it as the degree of centralization/ decentralization of decision rights (Zheng et al., 2010). The choice between a centralized and decentralized organizational structure is an age-old debate in academic literature with the advantages and disadvantages of each being documented extensively (Jensen and Meckling, 1995). Considering the domain of SCM, centralization concerns the extent to which the power to make SCM decisions is concentrated in a company (Kim, 2007). Studies have also tried to identify the relationship of SCM governance structures on performance by examining if organizational goals are achieved. Baier et al. (2008) demonstrate that in certain circumstances alternative forms of organizational structure are more appropriate in enabling purchasing alignment, thus situating it as an important contingency factor. Hence, we argue that the allocation of decisions rights for SCM activities will influence purchasing alignment.

The role of organizational size as a contingency factor has been examined in numerous studies in the area of business-IT alignment (Raymond and Bergeron, 2008).

Chan et al. (2006) have claimed that small firms may be better aligned because of the high level of communication between individuals while in larger ones, achieving a state of fit between business and IS/IT seems to be an arduous task. Surveying past studies, Chan and Reich (2007) debated on this issue, pinpointing that alignment actually increased with firm size in certain circumstances. A possible explanation as to why larger organizations achieve higher levels of alignment can be attributed to their use of formal processes and structures which facilitates it. However, studies which have aimed to examine and explain the causal impact of enterprise size have failed to discover to what extent and how it may impact alignment. The ambiguity of past findings suggests that in certain contexts organizational size is a strong predictor of alignment while in others the causal relationship is dampened.

\subsubsection{Purchasing decisions.}

Strategic decisions refer to choices made by top management which have a longterm impact on the operations and performance of an organization. The notion of strategic management entails the formulation of such strategic decisions, and describes the way by which a firm positions itself to the external environment. These types of decisions are predominantly performed at the top level of the hierarchy of management (Hambrick et al., 2005). Strategic alignment has been proven to be a result of the various strategic decisions that constitute the strategy of a firm, thus signifying the importance of coherent choices made by top management in relation to its external environment and other situational elements (Chan et al., 2006). 
Mikalef, P., Pateli, A., Batenburg, R.S., Wetering, R. van de. Purchasing alignment under multiple contingencies: a configuration theory approach. Industrial Management and Data Systems: 2015, 115(4), 625-645

Within the SCM domain there is support for this statement, with studies showing that strategic decisions have an impact on purchasing alignment (Baier et al., 2008). We therefore examine core decisions of the purchasing process as described by van Weele (2009). Additionally, decisions can be easily altered, thus their inclusion in the study acts as a roadmap for managers to develop coherent and well aligned purchasing strategies. Consequently, we distinguish between strategic purchasing decisions concerning the establishment of long-/short-term contracts with suppliers, adopting a supplier strategy based on multi- vs single sourcing, and formulating procurement automation mechanisms with preferred suppliers (van Weele, 2009).

\section{DATA COLLECTION AND MEASUREMENT}

\subsection{Data collection}

In order to actualize the objectives of the previous sections and test for configurations of elements that lead to enhanced purchasing alignment, data obtained from firms operating in Europe. The target population consisted of firms that have deployed IT systems for the purchasing function and belong to different industry domains and size categories. Respondents were asked to fill out custom built questionnaires through two-hour sessions held at the Department of Information and Computing Sciences of Utrecht University. Their participation was solicited through the social and business networks of Business Informatics students at the Utrecht University. This form of data collection is known as convenient sampling (Triola, 2004). In order to control nonresponse bias, firm representatives that did not attend the direct sessions despite being invited, were asked to either fill out a digital questionnaire or participate in a brief phone interview covering the main topics of the research study. Additionally, we conducted two split sample comparisons to verify that no significant differences existed within our data set. The first examined a sample of answers from respondents that attended the session compared to those filled through the digital questionnaire, while the second compared differences between firms that. Furthermore, we employed Harman' s single factor test for the ex post examination of common method variance (CMV) which showed that items did not load onto one construct, verifying that CMV is not a pervasive issue (Chang et al., 2010). The target population comprised of purchasing managers or personnel that were highly knowledgeable about the process.

Data gathering was performed over a period of three years commencing in 2008, and resulted in a sample of 172 companies from a total of 194 initial contacts (Table I). [Table 1]

A preliminary version of the questionnaire was reviewed by a group of procurement experts through interviews in order to validate its adherence to the constructs to be tested. Our sample covered the entire range of enterprise sizes from micro to large. We adopted this categorization in accordance with the size-class proposed by the European Commission Recommendation of 6 of May 2003 (2003/361/EC) with the group of large (+250 employees) firms accounting for 52.9 per cent of the sample, medium (50-249 employees) at 16.3 per cent, small (ten-49 employees) 24.7 per cent, and micro (one to nine employees) at 6.1 per cent.

\section{[TABLE 1]}


Mikalef, P., Pateli, A., Batenburg, R.S., Wetering, R. van de. Purchasing alignment under multiple contingencies: a configuration theory approach. Industrial Management and Data Systems: 2015, 115(4), 625-645

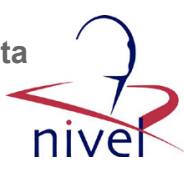

\subsection{Methodology}

We applied fsQCA, which allows for outcome and predictor variables to be on a fuzzy scale (continuous) rather than on just a dichotomous scale (binary). FsQCA seeks patterns of elements that lead to a specific outcome rather than just identifying correlations between independent and dependent variables. In addition, it enables the reduction of elements for each pattern, so configurations only include necessary, and sufficient conditions. Therefore, a distinction between core, peripheral and "don ' $\mathrm{t}$ care" aspects is developed, in which core and peripheral elements may be marked by their presence or their absence in explaining an outcome measure. Core elements are those that have a strong causal condition with the outcome of interest, while peripheral elements are those for which the causal relationship with the outcome is weaker (Fiss, 2011).

The first step in the analysis was to define outcome and independent measures, and to calibrate them into fuzzy sets with values ranging from 0 , which denotes no set membership to 1 , which is a connotation for full set membership. Consequently values can be on a continuous scale (0-1) indicating the level of membership to the variable at hand. The process of transforming a variable to a fuzzy set is done by the fsQCA software tool; however, thresholds must be set by the researcher for full and absence memberships as well as for scale mid-points. Once all elements are calibrated into fuzzy sets, the fsQCA algorithm can be applied producing a truth table of $2 \mathrm{k}$ rows, where $\mathrm{k}$ is the number of predictor elements, and each row indicates a possible combination. Since some combinations may not occur within the sample, these rows are omitted leaving only cases with at least one observation. At this stage the number of rows is further reduced according to the frequency of each case which is set to a minimum of 2 , and the degree of consistency, with a threshold of 0.75 (Ragin, 2006). Consistency is a measure that reflects the degree to which cases relate to set-theoretic relationships of a chosen solution (Fiss, 2011). Hence, by omitting cases that do not adhere to the above criteria it is possible to proceed to the construction of the truth table. By means of counterfactual analysis of causal conditions, core, and peripheral causes are outlined.

\section{[TABLE 2]}

\subsection{Outcome variable (purchasing alignment)}

Similarly to the procurement alignment framework (Beukers et al., 2006) which identifies domains within a business that must be in balance; we build the concept of purchasing alignment upon the dimensions that Turban et al. (1999) define. Hence, the purchasing and supply management domain can be distinguished into actions relating to strategy, processes, control, organization, information, and IT. The main proposition of the procurement alignment framework is that management should aim for the development of coherent and mutually supportive functional domains in order to realize performance gains. Accordingly, we define purchasing alignment as the degree of balance between the six dimensions within the purchasing and supply management domain. Although alignment under these dimensions has been empirically put to test in a number of contexts, the underlying contingencies that shape purchasing alignment still remain under-researched (Mikalef et al., 2013). 
Mikalef, P., Pateli, A., Batenburg, R.S., Wetering, R. van de. Purchasing alignment under multiple contingencies: a configuration theory approach. Industrial Management and Data Systems: 2015, 115(4), 625-645

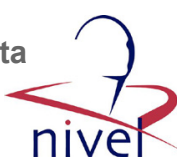

Purchasing alignment is developed as a second-order latent construct similarly to past studies (Batenburg and Versendaal, 2008). For each of the six aforementioned dimensions, a number of questions were formulated as items with five-point scale answer categories. The five-point scale was developed in congruency with the stages of purchasing maturity as defined by Van Weele and Rietveld (2000) and operationalized by Luftman (2000). Thus, a value of 1 denotes a low level of maturity in the specific domain, and 5 reflects a high degree of sophistication. Table III summarizes the scores and the descriptive statistics of the separate items (listed as keywords). In order to identify a possible internal inconsistency, the Cronbach' $\mathrm{s} \alpha$ test is applied. However, in cases where there are only two items that comprise a construct, the Spearman-Brown prediction test was preferred (Eisinga et al., 2012). Reliability tests confirm that the dimensions are consistent constructs since the Cronbach' s $\alpha$ and Spearman-Brown Coefficient were greater than 0.70 and all average inter-item correlations are significant. In order to measure purchasing alignment, we applied the following formula which calculates the standard deviation between the scores of each firm on the six purchasing dimensions (Batenburg and Versendaal, 2008): Alignment $1 / 41$ stdevðS; P; C;O; I ; ITP where S is the Strategy, $\mathrm{P}$ the Processes, $\mathrm{C}$ the Control, $\mathrm{O}$ the Organization, I the Information and IT $1 / 4$ Information Technology.

The higher the standard deviation between the scores on the six dimensions, the higher the misalignment, i.e. the lower the (purchasing) alignment expressed as the inverse of the misalignment score. Since there is no universal value to denote a high or low degree of purchasing alignment, we split the values into percentiles in order to set thresholds for fuzzy memberships. The most widely used method in such cases is to split outcomes into four equal groups of percentiles and set thresholds accordingly (Fiss, 2011). Therefore, we set the 75th percentile as the cross-over point for full membership (set as 1 - high purchasing alignment) with regard to purchasing aligned companies, the 50th percentile as the cut-off point at which we consider that there is an absence of alignment (coded as 0 - low purchasing alignment), and a median value between the two percentiles as the cross-over point.

\section{[TABLE 3]}

\subsection{Independent variables}

Strategic orientation was measured based on the three value disciplines proposed by Treacy and Wiersema (1993). The three disciplines, namely are operational excellence, customer intimacy, and product leadership are presented as mutually exclusive options to respondents. The calibration was done by constructing three variables, each representing the proportional strategic orientation with presence (1) or absence ( 0$)$ as possible choices.

Organizational size is measured based on a firm' s number of full time employees, with groupings developed in accordance to the European Union enterprise size classes $(1-9,10-49,50-249,250+)$. For the calibration into fuzzy sets, firms with more than 250 employees were coded as fully in the set of large firms (large size), those with 49 or less as fully out (small size) and the midpoint was set to 50 employees. With regard to purchasing structure, respondents were presented with 
Mikalef, P., Pateli, A., Batenburg, R.S., Wetering, R. van de. Purchasing alignment under multiple contingencies: a configuration theory approach. Industrial Management and Data Systems: 2015, 115(4), 625-645

one question on a three-level ordinal scale, from centralized ( 1 - all purchases are executed by the procurement department) to decentralized ( 3 - purchasing is coordinated locally by each department), with the mid value representing a hybrid mode (2).

Regarding purchasing decisions, we make use of three variables which are of central importance during the purchasing strategy formation phase as noted by van Weele (2009). We distinguish between purchasing decisions concerning the establishment of long-/short-term contracts with suppliers (contract binding), adopting a supplier strategy based on multi- vs single sourcing (large supplier base), and formulating procurement automation mechanisms with preferred suppliers (purchase repetitiveness). Contract binding was quantified as the distribution of the different contracts, as percentages, that firms sign with their suppliers. Respondents were asked to provide a distribution (0-100 per cent) of the number of purchases with no formal contract, preferred supplier agreements, window contracts which include logistical, legal and quality agreements, window contracts with additional performance indicators, and strategic partnership contracts. A weighted value was then calculated on a scale from 1 to 5 , assuming that strategic partnership contracts are the most binding and no formal contract the least. This value is an outcome based the sum of the percentages of contracts in each category multiplied, by the likert scale value associated with each category ranging from 1 to 5 . Consequently, values ranged on a continuous scale from 1 to 5 . For the transformation of the variable into a set, we constructed the element contract binding with full membership values being above 4, non-membership below 2, and the cross-over point at 3 .

The adoption of a multi- vs single sourcing purchasing strategy was quantified as the number of active suppliers. Respondents were instructed to select a numerical range based on estimations of suppliers of whom they had received an invoice within the last 12 months. For the calibration into sets, the variable large supplier base was coined, with full membership values being above 1,500 suppliers, the threshold for absence at less than 200 suppliers and the mid-scale at 500-1,000 suppliers. Procurement automation was measured as the degree of purchase repetitiveness, with respondents having to estimate the percentage of initial purchases (new supplier), modified repetitive purchases (new product or new supplier), and repetitive purchases (known supplier). Similarly, a weighted sum was calculated, based on the percentages selected and multiplied by the coefficient for each answer (1 denoted a new supplier, and three a repetitive purchase), with derived values ranging on a continuous scale from 1 to 3 . For the calibration into fuzzy sets, full membership of purchase repetitiveness was set to 2.5 , non-membership at 1.5 , and the mid-point threshold at 2.

\section{FINDINGS}

Outcomes of the fuzzy set analysis for high purchasing alignment firms are presented in Table IV. The black circles $(\bullet)$ denote the presence of a condition, while the crossed-out circles ( $\otimes$ ) indicate the absence of it (Ragin and Fiss, 2008). Core elements of a configuration are marked with large circles, peripheral elements with small ones, and blank spaces are an indication of a do not care situation in which the causal condition may be either present or absent. 
Mikalef, P., Pateli, A., Batenburg, R.S., Wetering, R. van de. Purchasing alignment under multiple contingencies: a configuration theory approach. Industrial Management and Data Systems: 2015, 115(4), 625-645

Solutions are enumerated according to the strategic orientation that a company employs resulting thus in 3 sets of solutions as well as a fourth one which can be applied for any strategic orientation. The solution table includes values of settheoretic consistency for each configuration as well as for the overall solution, with all values being above threshold (W0.75). Consistency measures the degree to which a subset relation has been approximated, whereas coverage assesses the empirical relevance of a consistent subset (Ragin, 2006; Mendel and Korjani, 2012). The overall solution coverage provides an indication as to what extent high purchasing alignment can be determined based on the set of configurations, with a value of 0.334 denoting a 33.4 per cent explanation of the samples outcome. Solutions $1 \mathrm{a}$ and $1 \mathrm{~b}$ indicate configurations of high purchasing alignment for firms that follow an operational excellence strategic orientation. The first (1a), indicates that the core condition to achieve this desired state is by avoiding a large size, and is thus applicable for small-sized enterprises. Additionally, combining the purchasing centralization with contracts that are binding for suppliers in terms of Service-Level Agreements (SLA), and repeating purchases with those specific ones are considered as conditions of lesser importance. The second solution includes strong contract binding between partners as a fundamental condition, and a large organizational size, a decentralized purchasing structure, a large supplier base and repetitive purchases as peripheral elements.

In the case of companies following a product leadership strategic orientation, the two solutions have identical core values but differ regarding peripheral configurations, thus falling into the category of neutral permutations. For companies engaging in product leadership strategic orientation, the conditions to be highly aligned are large size, absence of centralized purchasing structure, and large supplier base. Specifically, two solutions of peripheral elements arise. In Solution 2a, the combination of strong contract binding with an absence of purchasing repetitiveness form the constellation of peripheral elements. In Solution $2 b$ the opposite is true, $a$ combination of repetitive purchasing and a lack of strong binding contracts form the peripheral elements.

For companies following a customer intimacy strategic orientation, only one solution leads to high purchasing alignment. In this, organization size is indifferent.

The core elements that lead to high purchasing alignment are the centralization of the buying process accompanied by a large supplier base with an absence of contract binding. Additionally, not engaging in repetitive purchases is a peripheral condition to the solution.

Last, Solution 4 provides a pattern of elements in which strategic orientation is of no importance and can therefore be applied in any case or in firms that select a hybrid mode of strategy. In configuration four, companies that are not of a large size and combine their purchases with highly binding contracts manage to attain high level of purchasing alignment. Peripheral elements of this solution include the centralization of the buying process, a small supplier base and repetitive purchases. 
Mikalef, P., Pateli, A., Batenburg, R.S., Wetering, R. van de. Purchasing alignment under multiple contingencies: a configuration theory approach. Industrial Management and Data Systems: 2015, 115(4), 625-645

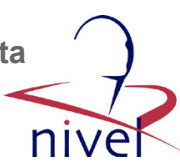

\section{[TABLE 4]}

\section{CONCLuSions}

In contrast with past studies, the approach we adopt does not consider alignment a result of a unique combination of specific elements, but rather that it can be attained in a number of ways. Therefore, we assimilated contingency elements that are regarded as important predictors of purchasing alignment relating to strategic orientation, organizational factors, and purchasing decisions. The selection of the specific groupings and the variables that comprise them was reinforced by past studies linking them with alignment. By applying the fsQCA methodology we arrive at six configurations of elements which result in superior purchasing alignment. We group these into four clusters of patterns based on the strategic orientation that a firm follows.

For companies following an operational excellence strategic orientation, high levels of purchasing alignment can be attained through two different ways. In both cases, purchasing repetitiveness and strong contract binding are necessary conditions. These strategic decisions can be translated as a high degree of system integration with preferred suppliers and the formation of SLAs regarding delivery efficiency and quality control on purchased items. Therefore, the way by which IT is managed is of critical importance since it must enable efficiency in operations while adhering to certain quality criteria. These type of contract arrangements are confirmed in past studies to be more suitable for companies following an operational excellence strategic orientation (Hoogeweegen et al., 2006). This is explained by the fact that through tight integration with preferred suppliers, it is possible for them to lower variable costs of executing orders and reducing delivery cycles. Since the main focus of operational excellence companies is to provide customers with reliable products and services against competitive prices and convenience, they are primarily concerned in increasing investments in their own core capabilities, slashing variable costs (Treacy andWiersema, 1993). In terms of organizational size, SMEs of the operational excellence strategic orientation benefit most by centralizing their purchasing decisions, while for large enterprises a decentralized purchasing structure is more favourable. Since larger firms are more likely to have a broader product portfolio with separate division responsible for each, a decentralized buying structure is considered as more efficacious, with the opposite applying for SMEs (Zahra et al., 2000).

For companies adopting the product leadership strategic orientation, our research suggests that large organizations are more prone to attain high levels of purchasing alignment. Possible explanations as to why large firms are more likely to achieve alignment have been provided in past literature (Chan and Reich, 2007). According to an aggregation of past findings, companies that do not belong to the large sizeclass have less formal rules for operation management, and thus have difficulties leveraging their purchasing systems. Additionally, it is likely that such companies may not have the capacity to employ staff that is proficient in executing digital purchasing strategies as opposed to large firms (Hoogeweegen et al., 2006). Equally as important for product leadership companies is the choice of opting for a large supplier base and decentralizing the purchasing process. This finding can be justified 
Mikalef, P., Pateli, A., Batenburg, R.S., Wetering, R. van de. Purchasing alignment under multiple contingencies: a configuration theory approach. Industrial Management and Data Systems: 2015, 115(4), 625-645

by the innovation-oriented nature of such firms, which requires them to be able to deliver new products before competitors.

Strong binding with a small number of suppliers may restrict the competitive actions that these firms undertake in the face of changing products or services. Hence, in order to reduce supply risk in new product development efforts, companies adhering to this strategic orientation must maintain a large supply base (Choi and Krause, 2006). Additionally, the rapid execution of purchasing orders requires a nonhierarchical structure of buying, in which each sub-unit can perform purchases according to requirements. This type of structure significantly reduces reaction times and time-to-purchase, thus minimizing the risk of supply scarcity (Jammernegg and Kischka, 2005).

The third solution concerns companies that adhere to the customer intimacy strategic orientation. This principle places a great deal of importance on understanding and fulfilling customer needs on demand. Companies engaging in this strategic orientation must be structured in such a way that allows for selecting through a large base of suppliers for the most suitable in each case, since customer demands frequently change (Hoogeweegen et al., 2006). The underlying reason for this requirement is the focus on tailored-made products/services, therefore a large supplier base must be available in order to be capable of providing the necessary raw materials to fulfil these demands. Additionally, the absence of contract binding is considered as an imperative condition. This is complementary to the large supplier base, since companies of the customer intimacy strategic orientation are benefited by ad-hoc relationships with suppliers. When customer requirements shift, the products/services offered by suppliers are very likely to be rendered obsolete. Past studies confirm that stable business networks of organizations are less suitable since an actually formulated customer order determines which organizations are required to fulfil this order (Hoogeweegen et al., 2006). After an order has been fulfilled, network ties with suppliers must easily dissolve, allowing for the formation of new arrangements to be made according to customer preferences (Snow and Miles, 1992). Additionally, a centralized structure is considered as being more efficient regarding control over sources of supply, and therefore is beneficial for customer intimacy firms (Croom, 2000). This formula for high levels of purchasing alignment is size-independent meaning that it applies for SMEs as well as for large companies.

The last solution is not dependent upon a specific strategic orientation and can therefore be applied to companies following hybrid modes of strategic orientation. This configuration of high purchasing alignment concerns SMEs, in which contract binding is regarded as a core condition, with high purchasing centralization, a small supplier base, and high purchase repetitiveness being peripheral conditions. The combination of these elements indicates that these SMEs are ones that focus on having a low cost and efficient purchasing operation with a small number of preferred suppliers. For these companies, purchasing alignment is contingent upon finding suppliers that adhere to their requirements and forming tight bonds with them through integration and automation.

The above configurations prove that alignment is not a result of a specific one-forall formula, but rather, it is dependent upon numerous synergistic elements. 
Mikalef, P., Pateli, A., Batenburg, R.S., Wetering, R. van de. Purchasing alignment under multiple contingencies: a configuration theory approach. Industrial Management and Data Systems: 2015, 115(4), 625-645

According to El Sawy et al. (2010), IS studies should consider this type of research and complement linear models when examining complex phenomena. To our knowledge, this study is the first to set purchasing alignment as the outcome towards examination and apply fsQCA methods to investigate the elements that it is contingent upon. In this respect our contribution to existing research lies in that we examine alignment as being an outcome of different predictors which are normally examined as controls. The presence of such elements that exhibit non-linear associations with alignment has been documented in literature reviews (Chan and Reich, 2007), however, to our knowledge there have been no empirical studies that examine their combined effect. Despite the novel methodological technique that our study employs, our findings are restricted to the domain of purchasing and SCM. Furthermore, we have only selected to examine a certain set of predictor variables leaving out others which may prove to have a greater impact on purchasing alignment. It may be beneficial for future studies engaging in such types of research in specific domains to include more context-specific elements in solutions. Such an approach would also be of more value to practitioners, since they could easily identify configurations in which their company fits, and make the necessary changes if any deviations are spotted in order to improve their business-IT alignment.

\section{REFERENCES}

Baier, C., Hartmann, E. and Moser, R. (2008), "Strategic alignment and purchasing efficacy: an exploratory analysis of their impact on financial performance" , Journal of Supply Chain Management, Vol. 44 No. 4, pp. 36-52.

Batenburg, R. (2007), "E-procurement adoption by European firms: a quantitative analysis ” , Journal of Purchasing \& Supply Management, Vol. 13 No. 3, pp. 182-192.

Batenburg, R. and Versendaal, J. (2008), "Maturity matters: performance determinants of the procurement business function" . ECIS 2008: Proceedings of the 16th European Conference on Information Systems, Galway, pp. 563-574.

Beukers, M., Versendaal, J., Batenburg, R. and Brinkkemper, S. (2006), "The procurement alignment framework construction and application” , Wirtschaftsinformatik, Vol. 48 No. 5 , pp. 323-330.

Chae, H.C., Koh, C.E. and Prybutok, V.R. (2014), "Information technology capability and firm performance: contradictory findings and their possible causes” , MIS Quarterly, Vol. 38 No. 1, pp. 305-326.

Chan, Y.E. and Reich, B.H. (2007), "IT alignment: what have we learned?" , Journal of Information Technology, Vol. 22 No. 4, pp. 297-315.

Chan, Y.E., Sabherwal, R. and Thatcher, J.B. (2006), "Antecedents and outcomes of strategic IS alignment: an empirical investigation” , IEEE Transactions on Engineering Management, Vol. 51 No. 3, pp. 27-47.

Chang, S.J., Van Witteloostuijn, A. and Eden, L. (2010), "From the editors: common method variance in international business research" , Journal of International Business Studies, Vol. 41 No. 2, pp. 178-184.

Chen, L. (2010), "Business - IT alignment maturity of companies in China" , Information \& Management, Vol. 47 No. 1, pp. 9-16.

Choi, T.Y. and Krause, D.R. (2006), "The supply base and its complexity: implications for transaction costs, risks, responsiveness, and innovation" , Journal of Operations Management, Vol. 24 No. 5, pp. 637-652. 
Mikalef, P., Pateli, A., Batenburg, R.S., Wetering, R. van de. Purchasing alignment under multiple contingencies: a configuration theory approach. Industrial Management and Data Systems: 2015, 115(4), 625-645

Cousins, P.D. (2005), “The alignment of appropriate firm and supply strategies for competitive advantage" , International Journal of Operations \& Production Management, Vol. 25 No. 5, pp. 403-428.

Cragg, P., King, M. and Hussin, H. (2002), "IT alignment and firm performance in small manufacturing firms” , Journal of Strategic Information Systems, Vol. 11 No. 2, pp. 109132.

Croom, S.R. (2000), "The impact of web - based procurement on the management of operating resources supply" , Journal of Supply Chain Management, Vol. 36 No. 1, pp. 413.

Devaraj, S. and Kohli, R. (2003), "Performance impacts of information technology: is actual usage the missing link?” , Management Science, Vol. 49 No. 3, pp. 273-289.

Donaldson, L. (2001), The Contingency Theory of Organizations, Sage, Thousand Oaks, CA.

Eisinga, R., Grotenhuis, M.T. and Pelzer, B. (2012), "The reliability of a two-item scale: Pearson, Cronbach, or Spearman-Brown?” , International Journal Of Public Health, Vol. 58 No. 4, pp. 637-642.

El Sawy, O.A., Malhotra, A., Park, Y. and Pavlou, P.A. (2010), "Seeking the configurations of digital ecodynamics: it takes three to tango" , Information Systems Research, Vol. 21 No. 4, pp. 835-848.

Fiss, P.C. (2007), "A set-theoretic approach to organizational configurations" , Academy of Management Review, Vol. 32 No. 4, pp. 1180-1198.

Fiss, P.C. (2011), "Building better causal theories: a fuzzy set approach to typologies in organization research" , The Academy of Management Journal (AMJ), Vol. 54 No. 2, pp. 393-420.

Gregor, S. (2006), "The nature of theory in information systems" , MIS Quarterly, Vol. 30 No. 3, pp. 611-642.

Hambrick, D.C., Finkelstein, S. and Mooney, A.C. (2005), "Executive job demands: new insights for explaining strategic decisions and leader behaviors" , Academy of Management Review, Vol. 30 No. 3, pp. 472-491.

Heckman, R. (1999), "Managing the IT procurement process" , Information Systems Management, Vol. 16 No. 1, pp. 61-71.

Henderson, J.C. and Venkatraman, N. (1993), "Strategic alignment: leveraging information technology for transforming organizations” , IBM Systems Journal, Vol. 32 No. 1, pp. 472484.

Ho, C.F., Wu, W.H. and Tai, Y.M. (2004), "Strategies for the adaptation of ERP systems" , Industrial Management \& Data Systems, Vol. 104 No. 3, pp. 234-251.

Hoogeweegen, M.R., van Liere, D.W., Vervest, P.H., van der Meijden, L.H. and de Lepper, I. (2006), "Strategizing for mass customization by playing the business networking game" , Decision Support Systems, Vol. 42 No. 3, pp. 1402-1412.

Jammernegg, W. and Kischka, P. (2005), "Dynamic, customer-oriented improvement of supply networks” , European Journal of Operational Research, Vol. 167 No. 2, pp. 413426.

Jensen, M.C. and Meckling, W.H. (1995), "Specific and general knowledge, and organizational structure” , Journal of Applied Corporate Finance, Vol. 8 No. 2, pp. 4-18.

Kim, S.W. (2007), "Organizational structures and the performance of supply chain management” , International Journal of Production Economics, Vol. 106 No. 2, pp. 323345.

Luftman, J. (2000), "Assessing business-IT alignment maturity" , Communications of the Association for Information Systems, Vol. 4 No. 14, pp. 1-50.

Mendel, J.M. and Korjani, M. (2012), "Charles ragin' s fuzzy set qualitative comparative analysis (fsQCA) used for linguistic summarizations" , Information Sciences, Vol. 202, pp. 1-23, available at: www.sciencedirect.com/science/article/pii/S0020025512001594 Mikalef, P. and Pateli, A. (2011), "A systematic meta-analytic review on factors influencing the 
Mikalef, P., Pateli, A., Batenburg, R.S., Wetering, R. van de. Purchasing alignment under multiple contingencies: a configuration theory approach. Industrial Management and Data Systems: 2015, 115(4), 625-645

strategic alignment in service-oriented architecture projects" , Proceedings of the 6th Mediterranean Conference on Information Systems, Limassol, 4-5 September.

Mikalef, P., Pateli, A., Batenburg, R. and van de Wetering, R. (2013), "Investigating the impact of procurement alignment on supply chain management performance" , Proceedings of Conference on Enterprise Information Systems (CENTERIS), Lisbon, 23-25 October.

Mikalef, P., Pateli, A., Batenburg, R. and van de Wetering, R. (2014), "Business alignment in the procurement domain: a study of antecedents and determinants of supply chain performance" , International Journal of Information Systems and Project Management, Vol. 2 No. 1, pp. 43-59.

Miles, R.E. and Snow, C.C. (1978), Organizational Strategy, Structure and Process, McGraw-Hill Book Co., New York, NY.

Milgrom, P. and Roberts, J. (1995), "Complementarities and fit strategy, structure, and organizational change in manufacturing" , Journal of accounting and economics, Vol. 19 No. 2, pp. 179-208.

Papp, R. (1999), “Business-IT alignment: productivity paradox payoff?” , Industrial Management \& Data Systems, Vol. 99 No. 8, pp. 367-373.

Park, Y.K. and El Sawy, O.A. (2012), "Discovering the multifaceted roles of information technologies with a holistic configurational theory approach" , Proceedings of the 45th Hawaii International Conference on System Sciences, pp. 5204-5212.

Peak, D., Guynes, C.S. and Kroon, V. (2005), "Information technology alignment planning a case study” , Information \& Management, Vol. 42 No. 5, pp. 635-649.

Porter, M.E. (1980), Competitive Strategy: Techniques for Analysing Industries and Competitors, Free Press, New York, NY.

Presutti, W.D. (2003), "Supply management and e-procurement: creating value added in the supply chain” , Industrial Marketing Management, Vol. 32 No. 3, pp. 219-226.

Ragin, C.C. (2006), "Set relations in social research: evaluating their consistency and coverage” , Political Analysis, Vol. 14 No. 3, pp. 291-310.

Ragin, C.C. and Fiss, P.C. (2008), "Net effects analysis versus configurational analysis: an empirical demonstration” , in Ragin, C.C. (Ed.), Redesigning Social Inquiry: Fuzzy Sets and Beyond, Chicago: University of Chicago Press, Chicago, IL, pp.190-212.

Raymond, L. and Bergeron, F. (2008), "Enabling the business strategy of SMEs through ebusiness capabilities: a strategic alignment perspective" , Industrial Management \& Data Systems, Vol. 108 No. 5, pp. 577-595.

Rihoux, B. and Ragin, C.C. (Eds) (2009), Configurational Comparative Methods: Qualitative Comparative Analysis (QCA) and Related Techniques, Sage, Thousand Oaks, CA.

Snow, C.C. and Miles, R.E. (1992), "Causes for failure in network organizations" , California Management Review, Vol. 34 No. 1, pp. 53-57.

Solow, R.M. (1987), "We' d better watch out” , New York Times Book Review, 12 July, p. 36, available at:www.emeraldinsight.com/doi/full/10.1108/02635571211232280 Sousa, R. and Voss, C.A. (2008), "Contingency research in operations management practices" , Journal of Operations Management, Vol. 26 No. 6, pp. 697-713.

Tallon, P.P. (2007), "A process-oriented perspective on the alignment of information technology and business strategy" , Journal of Management Information Systems, Vol. 24 No. 3, pp. 227-268.

Tan, F.B. (1995), "The responsiveness of information technology to business strategy formulation: an empirical study” , Journal of Information Technology, Vol. 10 No. 3, pp. 171-178.

Thompson, A.A., Strickland, A.J., Gamble, J.E. and Zeng' an, G. (2008), Crafting and Executing Strategy: The Quest For Competitive Advantage: Concepts and Cases, McGraw-Hill-Irwin, New York, NY. 
Mikalef, P., Pateli, A., Batenburg, R.S., Wetering, R. van de. Purchasing alignment under multiple contingencies: a configuration theory approach. Industrial Management and Data Systems: 2015, 115(4), 625-645

Thun, J.H. (2010), "Angles of integration: an empirical analysis of the alignment of internetbased information technology and global supply chain integration" , Journal of Supply Chain Management, Vol. 46 No. 2, pp. 30-44.

Treacy, M. and Wiersema, F. (1993), "Customer intimacy and other value disciplines" , Harvard Business Review, Vol. 71 No. 1, pp. 84-93.

Triola, M.F. (2004), Elementary Statistics, 9th ed., Pearson Education, Boston, MA.

Turban, E., McLean, E. and Wetherbe, J. (1999), Information Technology for Management: Making Connections for Strategic Advantage, John Wiley \& Sons, Chichester.

Van Weele, A.J. and Rietveld, G. (2000), "Professional development of purchasing in organisations: towards a purchasing development model” , in WMRC (Ed.), Global Purchasing and Supply Chain Strategies, Touch Briefings, London, pp. 170-175.

van Weele, A.J. (2009), Purchasing and Supply Chain Management: Analysis, Strategy, Planning and Practice, Cengage Learning EMEA, London.

Venkatraman, N. (1989), "The concept of fit in strategy research: toward verbal and statistical correspondence” , Academy of Management Review, Vol. 14 No. 3, pp. 423444.

Wong, C., Skipworth, H., Godsell, J. and Achimugu, N. (2012), "Towards a theory of supply chain alignment enablers: a systematic literature review" , Supply Chain Management: An International Journal, Vol. 17 No. 4, pp. 419-437.

Zahra, S.A., Neubaum, D.O. and Huse, M. (2000), "Entrepreneurship in medium-size companies: exploring the effects of ownership and governance systems" , Journal of management, Vol.

26 No. 5, pp. 947-976.

Zheng, W., Yang, B. and McLean, G.N. (2010), "Linking organizational culture, structure, strategy, and organizational effectiveness: mediating role of knowledge management" , Journal of Business Research, Vol. 63 No. 7, pp. 763-771.

\section{TABLES AND FIGURES}

TABLE I. FREQUENCY OF RESPONSES BY RESPONDENTS' POSITION

\begin{tabular}{lrr}
\hline Respondents position & Frequency & $\%$ \\
\hline Procurement director & 27 & 15.7 \\
Supply chain manager & 14 & 8.1 \\
Purchasing manager/head of procurement & 39 & 22.7 \\
Initial buyer/strategic buyer & 20 & 11.6 \\
Purchasing analyst/supply chain analyst & 21 & 12.2 \\
Assistant buyer/administrative buyer/logistical buyer & 16 & 9.3 \\
Procurement employee(facilitating) & 14 & 8.1 \\
Controller & 9 & 5.2 \\
Boardroom director (no procurement director) & 12 & 7.0 \\
Total & 172 & 100.0
\end{tabular}


Mikalef, P., Pateli, A., Batenburg, R.S., Wetering, R. van de. Purchasing alignment under multiple contingencies: a configuration theory approach. Industrial Management and Data Systems: 2015, 115(4), 625-645

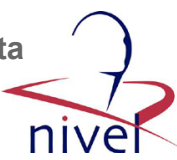

TABLE II. FREQUENCY OF RESPONSES BY BUSINESS SECTOR

\begin{tabular}{lrr}
\hline Business Sector & Frequency & $\%$ \\
\hline (Semi) process industry & 20 & 11.6 \\
Discrete parts production (unit- and mass production) & 19 & 11.0 \\
Utilities sector & 6 & 3.5 \\
Construction & 19 & 11.0 \\
Healthcare & 11 & 6.4 \\
Wholesale/retail & 33 & 19.2 \\
Logistics & 6 & 3.5 \\
Banking and insurance & 14 & 8.1 \\
Professional services & 23 & 13.4 \\
Government & 13 & 7.6 \\
Education & 8 & 4.7 \\
Total & 172 & 100.0
\end{tabular}

\section{TABLE III. DESCRIPTIVE STATISTICS FOR THE SIX DIMENSIONS FOR}

\section{PURCHASING MATURITY}

\begin{tabular}{lcccc}
\hline Dimension & Mean & SD & Cronbach's $\alpha$ & Spearman-Brown coefficient \\
\hline (1) Strategy & 3.14 & 1.14 & & 0.70 \\
Documentation and plans & 3.38 & 1.42 & & \\
Global sourcing & 2.91 & 1.38 & & \\
(2) Processes & 3.55 & 0.80 & 0.71 & \\
Product specification & 3.67 & 1.17 & & \\
Product selection & 3.74 & 1.05 & \\
Contracting & 3.40 & 1.05 & & \\
Ordering & 3.42 & 1.12 & \\
(3) Control & 3.18 & 0.94 & 0.72 & \\
Process control & 3.29 & 1.11 & & \\
Internal performance measuring & 3.18 & 1.32 & & \\
Supplier performance measuring & 3.07 & 1.09 & & \\
(4) Organization & 3.26 & 1.06 & \\
Purchasing department & 3.26 & 1.27 & \\
Staff competences & 3.27 & 1.23 & \\
(5) Information & 2.74 & 1.07 & \\
Information processing & 2.84 & 1.35 & \\
Management information & 2.65 & 1.15 & \\
(6) Information technology (IT) & 2.51 & 1.02 & \\
Operational purchasing Process & 2.80 & 1.32 & \\
Tactical purchasing process & 2.23 & 1.11 &
\end{tabular}

TABLE IV. CONFIGURATIONS FOR ACHIEVING HIGH LEVELS OF PURCHASING ALIGNMENT

\begin{tabular}{|c|c|c|c|c|c|c|c|}
\hline \multirow[b]{2}{*}{ Configuration } & & \multicolumn{6}{|c|}{ Solution } \\
\hline & & la & $1 \mathrm{~b}$ & $2 \mathrm{a}$ & $2 \mathrm{~b}$ & 3 & 4 \\
\hline $\begin{array}{l}\text { Strategic orientation } \\
\text { Operational excellence } \\
\text { Product leadership } \\
\text { Customer intimacy }\end{array}$ & & & & & & & \\
\hline $\begin{array}{l}\text { Organizational factors } \\
\text { Large size } \\
\text { Purchasing centralization }\end{array}$ & & $\otimes$ & $\bullet$ & & $\otimes$ & & $\underset{\bullet}{\otimes}$ \\
\hline $\begin{array}{l}\text { Purchasing decisions } \\
\text { Contract binding } \\
\text { Large supplier base } \\
\text { Purchase repetitiveness } \\
\text { Consistency } \\
\text { Raw coverage } \\
\text { Unique coverage } \\
\text { Overall solution consistency } \\
\text { Overall solution coverage }\end{array}$ & $\begin{array}{l}0.761 \\
0.334\end{array}$ & $\begin{array}{c}\bullet \\
\bullet \\
0.865 \\
0.074 \\
0.015\end{array}$ & $\begin{array}{c}\bullet \\
0.763 \\
0.056 \\
0.031\end{array}$ & $\begin{array}{l}\otimes \\
0.757 \\
0.066 \\
0.054\end{array}$ & $\begin{array}{l}\bullet \\
0.768 \\
0.023 \\
0.011\end{array}$ & $\begin{array}{c}\bigotimes \\
\otimes \\
0.947 \\
0.031 \\
0.031\end{array}$ & $\begin{array}{c}\otimes \\
\bullet \\
0.814 \\
0.073 \\
0.026\end{array}$ \\
\hline
\end{tabular}

